Globus Journal of Progressive Education

A Refereed Research Journal

Vol 10 / No 1 / Jan-Jun 2020

ISSN: 2231-1335

\title{
IM DEVELOPMENT FOR LITERARY CRITICISM AND TEACHING OF LITERATURE: CLASSROOM EXPERIENCE
}

*Aragon, Douglas Angel II A.

\begin{abstract}
With the advancement of technology and series of curriculum reform, teachers are challenged to recalibrate their teaching methodology and delivery of instruction. Teachers may adopt ways to improve the quality of instruction everyday. In order to achieve this goal, teachers may opt to use variety of instructional methods and techniques such as developing research-based instructional materials that will aid the current teaching-instruction modality. In this context, this paper aimed to develop an instructional material in Literary Criticism and Teaching of Literature to enhance instruction in these fields. The content of the proposed IM was based from CMO $30 \mathrm{~s}$. 2004 to align with the expected competency based standards for education students specializing English and Literature. There were 100 English majors used as respondents for the need assessment, grouped as follows: 57 freshmen, 33 sophomore and 10 juniors. These respondents noted that "learning is best achieved in the presence of sample output exercises reflected in the handouts (WM 1.29)" and "handouts promote the habit of self-individualized learning (WM 1.38)", lastly, "teaching the theories requires textbooks and references (WM 1.49)". All the responses fall in the interpretation of strongly agree. Three experts in the field evaluated the content validity of the two instructional materials: The Lectures on Discourse and Teaching of Literature. The instructional materials were evaluated on the following criteria: content, organization, effectivity and preference. The Lectures on Discourse was rated 4.30 while the Teaching of Literature was rated 4.28 both with an interpretation of very satisfactory, recommended for utilization if corrections are typographical in nature; then editors can correct them and return it to the writer then re-submit again the IM for further evaluation. Meanwhile, there were four selected stories used as specimen-texts for this study. The first layer of criticism used content thematic approach to identify the content, which discussed the cultural issues of the texts and the second layer used symptomatic reading to examine the deeper meaning. The actual experience of the respondents in doing the literary analysis provided the insight in establishing the chronology and suggested content of the lecture notes. The actual output from the literary analysis served as sample models in the exercises part. Homi Bhabha's (1994) postcolonial framework established the concept of postcolonial symptoms while Francis Johnson's (1975) framework established the framing of the
\end{abstract}

instructional material. At the end of this attempt, this paper hoped that it may open up a series of literary studies to other perspectives and multidisciplinary approaches and develop instructional materials generated from the exercises made by the students to serve as additional reference in appreciating literature and criticism particularly for a student-directed group environment.

Keywords: Instructional Material, Material Development, Postcolonialism.

\section{Introduction}

The Fourth Industrial Revolution continuously transforms the educational landscape. Educators are challenged by the demanding task of educating the millennial to keep them abreast with the digital world. EDCOM Report of 1991 reported that Philippine Education lags behind in producing graduates demonstrating expected competencies mandated by the course. The status of education today is influenced by several problems specifically the issue of inadequate instructional materials and teaching tools aligned to the learning outcomes prescribed by the Commission. Teachers find it difficult to teach some major subjects in English due to scarcity of relevant and research based learning materials. The learning process requires combination of lecture method and self-directed instruction in order to hone the holistic capability of the learners. Students are held accountable in coping with these expectations as part of training for lifelong learning. With these expectations, teachers may utilize number of instructional methods such as instructional module, lecture notes and the like. The modular instruction incorporates individualized instruction allowing students to attain needed competencies by proceeding at a pace consistent with the student's interest and abilities.

*College of Education, Central Bicol State University of Agriculture-Sipocot Campus, Sipocot, Camarines Sur 4408 
Meanwhile, in the context of developing the content of the instructional materials, the analysis of the respondents serve as models or pattern by the students on how the texts are analyzed through postcolonial framework. The selected texts revolve on identifying the Filipino identity and his hybridized existence because of the imperial influence on culture, practice, and mentality through colonization. Colonization has served as the great force in "othering" the indigenous practices and values of the colonized subject. The belief of the West in their superiority has led to the propagation of stereotypes that portray the colonized as inferior and strange. As a result, the colonized consciousness is silenced and challenged by these subjectification. These cultural issues will be examined from the selected texts generating the reflection of life put into act of mimicry by the fictional characters then mirrored by humans in real life situations. Finally, literary analysis is challenging particularly when the task is done alone. The necessity for providing means to appreciate literature in practical way, teachers in language and literature recognize that English majors need scaffold in doing literary analysis for them to appreciate literature at the end.

\section{Research Problem}

Grounded from the selected short stories, these stories described the experience of colonization and its impact to the sensibility of the colonized subject thereby illustrating how the selected stories establish the colonized sensibility and how this sensibilities share implications in a real life situation. Moreover, the actual experience of the respondents in evaluating the merit of literature serves as guide in developing a contextualized instructional material in Literary Criticism and Teaching of Literature. Specifically, it sought to answer the following objectives:

1. Determine the cultural issues emerged from the selected texts particularly the symptoms of colonized (Bikolano) sensibility;

2. Determine the educational implication of the cultural issues and sensibilities generated from the texts and its significance to the real life situation of the colonized subject;

3. Develop lecture note in Literary Criticism and Teaching of Literature from the experience and challenges encountered by the respondents in the process of evaluating the merit of literature; and

4. Determine the content validity of the lecture notes.

\section{Materials and Method}

In examining the postcoloniality of the selected texts, this study uses the postcolonial framework advanced by Homi Bhabha, a theory that appropriates Michel Foucault's notion of discourse as power, Jacques Lacan's subjectivity and Jacques Derrida's difference and supplementarity.

Homi K. Bhabha explained the dialectical relationship between the grafted European cultural systems and an indigenous culture in his concept of ambivalence and hybridity where he made it clear that cultures must be understood as complex intersections of multiple places, historical temporalities, and subject positions. Bhabha identified the ethnocentric blind spots and voluntarist rhetoric in what was regarded as the most radical critiques of liberal models of cultures, the possibility of "translation" and new way of thinking the dialectic between the general and the particular". In the process of translation, a generalized social situation of conflict is held together or motivated by distinctive rules like the use of the language. And this language could be a site of struggle or resistance as it shows discourse of truth. Following Foucault's notion that discourse creates power, which enables resistance, it follows then that the discourse of any text, like the selected texts, becomes the site of struggle.

Bhabha also argued that cultural hybridity and multiplicity is a product of an ambivalent signification. The colonial signifier - neither one nor other - is an act of ambivalent signification, which Bhabha calls "splitting". This notion of ambivalence or splitting is what Jacques Lacan identified as subjectivity. Lacan's fundamental contention in his theory of subjectivity is that the human subject is split into the conscious and unconscious part and that the subjectivity of the analyst and the analysand work on each other in the same way that the subjectivity of the colonizer and the colonized conquers each other. Since each person possesses his/her own subjectivity, the psychoanalytic encounter between the analyst and the analysand becomes the dialectical playing out of their subjectivities: the analyst works on the analysand and/or vice-versa. Bhabha calls this dialectical playing of subjectivities the transference between the colonizer and the colonized. The word "I" therefore reflects a part of both the colonizer or the colonized, since there is no pure culture, as a result of transference of culture through colonization. Thus no one can say that $\mathrm{s} / \mathrm{he}$ has a pure culture, the colonizer cannot anymore speak of himself/herself without the colonized and vice versa.

Lacanian psychoanalysis is applied in this study the way Bhabha used it to read postcolonial texts, by 
analyzing the subjectivities revealed in the texts through its content and form - metaphoric and metonymic images with which the colonized character identifies and summons the absent colonizer. This element of hybridity is prevalent in postcolonial and third world societies, like the Philippines where hybrid culture threads on the boundary between opposing cultures. This hybridity of emergent culture, however, is problematic. An emergent culture is always in motion opposing a dominant culture. In the process of opposition, the emergent culture remains, although in a concealed way entangled in a dominant. The continual motion means that there is always a constant change; there is always a direction. The entanglement with the dominant may weaken and the emergent may become the new dominant culture. Hence, while there is an element of hybridity in the nature of emergent culture, this hybridity is also in motion like in an open ended construct that the signifier may move to either end and it keeps on changing that it is difficult to catch it or paint a picture of it. But an object in motion always passes through particular points while it moves towards a certain direction. Bhabha further posits that the production of meaning requires that these two places be mobilized in the passage through a Third Space which represents both the general conditions of language and the specific implication of the utterance in a performative and institutional strategy of which it cannot 'in itself' be conscious and which this unconscious relation introduces an ambivalence in the act of interpretation.

In developing the content for the proposed lecture note, this study is also guided by Ausubel's Subsumption Theory, Vygotsky's Scaffold Learning Theory and Dewey's Constructivist Approach.

David Paul Ausubel (1978) argued that learning of new knowledge relies on what is already known, and the learners learn by constructing a network of concepts and adding to them. Given this assumption, Ausubel proposed the use advance organizer in order to help the learners to link new learning material with existing related ideas. He also argued that activities incorporated in the work-text are in the form of graphic organizers at every end of each lesson to develop the higher order thinking skills of the students.

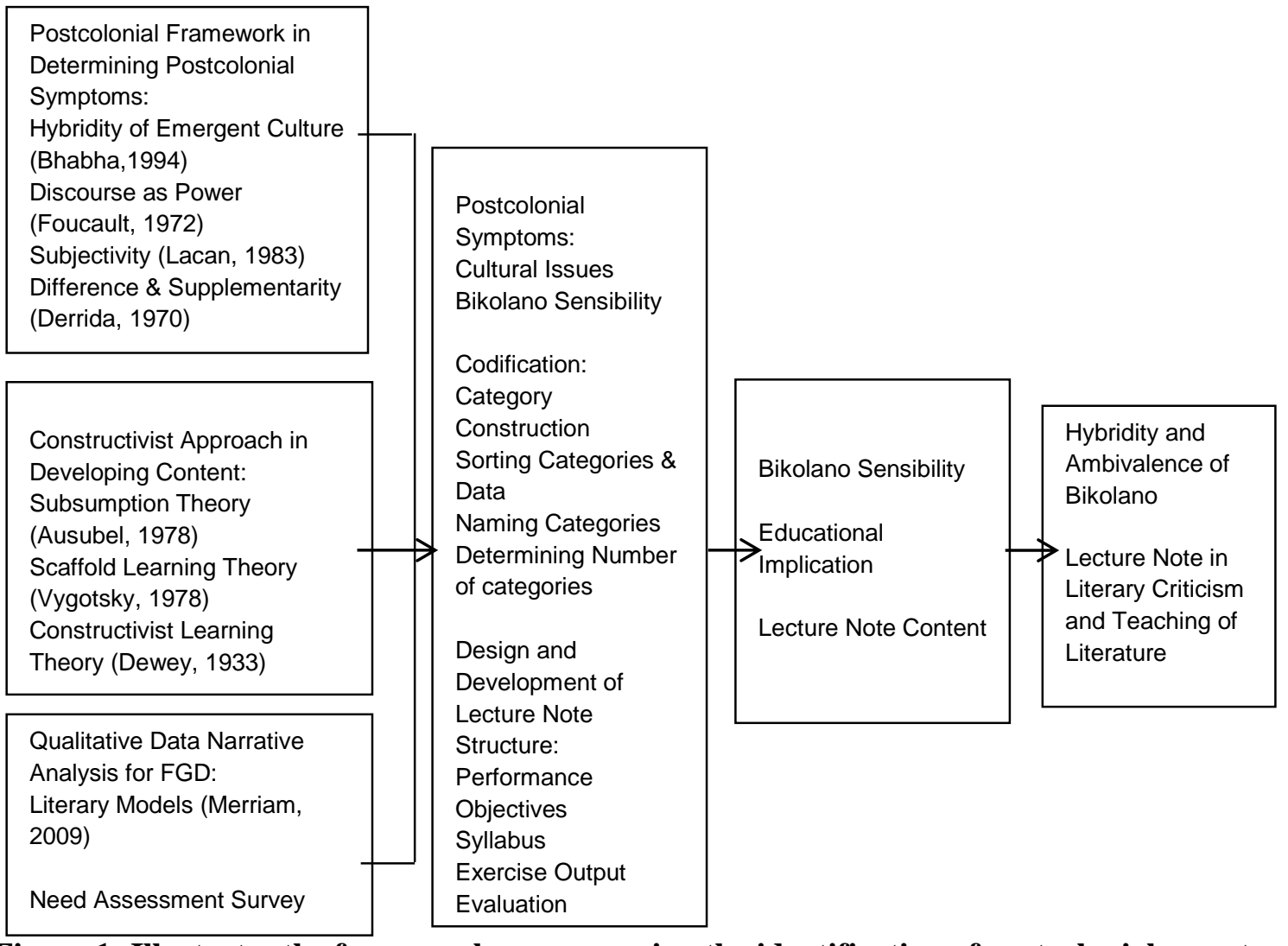

Figure 1: Illustrates the framework encompassing the identification of postcolonial symptoms and development of content for the two sets of lecture notes 
Lev Vygotsky (1978) in his Scaffold Learning Theory argues that one's acquiring of knowledge may be more successful when a scaffold assists the learning process. Vygotsky posits that once a student masters a given task with the help of scaffolding, the learner will then be able to complete the task again once the scaffolding has been removed. Based on this theory, it is believed that the instructional material will provide as scaffold to support for the teaching and learning process. On the other hand, the Constructivist Approach by John Dewey (1933) encompasses the two theories mentioned as a guide in this study because according Chopra and Gupta (2011), this approach implies direct experience with system as a process of acquiring knowledge in which prior concepts are explained and changed on the basis of fresh meaning from peers and teachers. Hence, constructivist approach is based on the idea that the learner forms his/her own knowledge through experiences. Basically, for learning to become effective, appropriate learning activities through direct instruction or student-directed environment should be carried out. These activities are based on the learner's engagements as proposed by constructivism. Hence, designing learning activities both for the two learner-environments require considerations of learning goals, materials and assessment practices. This study aims at analyzing literary texts in which the output of the respondents and the challenges they have encountered in the process of analysis shall be included as part of the proposed lecture note. The illustration below illustrates the arrangement and succession of activities of the study.

\section{Result and Discussion}

\section{Cultural Issues and Symptoms of Bikolano Sensibility: Hybridity, Ambivalence \& Displacement}

The themes in the selected texts are so closely interwoven because each text posits parallel postcolonial symptoms from hybridity, ambivalence to displacement of characters and assertion of Bikolano sensibility. Each story articulates the hybrid nature of Bikol characters which are not pulled apart but singing new songs, a new creation from or within the border. Bobis's characters like the local seer and fruit stall vendor prove their currency in the colonial context, the local chanter uses her multicultural characteristics in cultural negotiation, while the fruit seller uses her hybrid and ambivalent identity to mask her native mark. This is a notion of hybridity, which liberates the union of things that have been artificially separated and the Bikol migrant experience is one. The Bikol characters' displacement by geographic separation, culture or identity speaks nourishment of their hybridity in a foreign land or man's dominated culture as a totally fragmented Self, no longer pure but already an enriched hybrid.

Considering Bhabha's notion on ambivalence, hybridity and displacement, the characters establish the Bikolano sensibility in the colonized context on how to get along with the Westerns and adapt to the new environment or culture and yet retain their local culture. Each time this encounter between Self and Other occurs at the point at which something exceeds the frame of the image (as in the case of the stories analyzed in this selected texts), it evacuates the Self as the site of identity and autonomy and leaves a mark of the subject, a sign of cultural identity, the Bikolano sensibility. This becomes the moment in which the demand for identification takes the form of a response to other questions of signification and desire, culture, and politics. The author's use of Bikol or Filipino language in her texts asserts this question of signification, which speaks against the superiority of the Westerns (colonizers) over the Third World countries (colonized).

The four selected short stories namely: White Turtle, Fish Hair Woman, Fruit Stall and Border Lover) appropriated language to "bear the burden" of the colonial experience showing that the colonized subject has altered the prevailing paradigmatic norms of standard English and has proven what Bhabha calls the "supplementarity and hybridity of cultural translation and linguistic filiation." The author has also summoned the absent colonizer in the presence of the colonized Bikol characters through metaphoric and metonymic images such as "white turtle", to signify the dreams of the dead children and an alternative way of retelling stories, "fish-hair woman", for an icon of salvation and courage, "border lover", for the Bikol character who has learned Western education and culture and yet retains her native identity, and the "fruit seller", for the Bikol character who covers her Asian identity to live in a colonizer's country.

In consonance with Bhabha's assertion on identification that is never a priori, nor a finished product but only a site for ambivalence, it follows that a figure of contiguity that substitutes a part for a whole must not be read as form of simple substitution or equivalence but as a double movement that follows what Derrida calls the logic or play of the 'supplement'. Here, Bhabha stresses that the identity articulated by the colonized subject is not the single, coherent, and pure white-ideal ego proffered by the 
colonizer. Rather, the identity of the colonized subject articulated by the texts shows fragmentation, hybridity, multiplicity, and contradictions. And conversely, the identity of the colonizer himself is not coherent, pure, authentic, supreme Self from what he claims to be in Western discourse, but an ambivalent and fragmented identity characterized by hybridity, multiplicity, and contradictions. The preceding texts, therefore, in abrogating and appropriating Western discursive practices and in representing and addressing the colonizer through Western images with which the Bikol character likewise identifies, interrogate not merely an image of the colonial past but the power relations that enabled the discursive and disciplinary place from which questions of Bikolano sensibility may be strategically and institutionally posed. The selected texts attempt to locate the postcolonial subject in the hybrid gap, within the play of the subaltern instance of writing. She articulates the cultural difference as an enunciative category, which opposes the notion of cultural purity and supremacy and posits cultural difference and hybridity. These postcolonial symptoms are well articulated in the her texts like the "white turtle" as metaphor for the source of the stories, creative energy, inspiration and salvation and "Estrella - the fish hair woman" mirrors a strong woman, being the shaman of the village manifests bravery and strength compared to man, as she trawls dead bodies from the river. The grandmother in the story "Border Lover" typifies a strong interpellation of the stereotype being submissive and boxed inside the household chores while her grandchild who finished her doctoral studies in Australia brags to her the Western cultures, which shows that both characters are in the border of either the one or the other, that both characters posit identity which has traces of colonialism which they try to eliminate and yet present in their sensibilities. Because no matter how the writer tries to efface this cultural configuration in her stories, it evolves in her texts and no matter how she injects indigenous identity, what appears is a fragmented identity.

The author's abrogation and appropriation of language to suit the needs of the situation shows that the writer exercises a certain power that she has an access to various possibilities of using, developing and expanding the language. This further proves that English can never fully articulate the writer's sensibility, thus the Western notion of superiority of Received Standard English could be negated. Indeed, Bhabha's postcolonial framework reveals the notion of Bikolano sensibility asserted in four selected texts which articulate the different symptoms: hybridity, ambivalence and displacement. These postcolonial symptoms erase any essentialist claims for the inherent authenticity or purity or supremacy of cultures because one is enabled by the Other. Hence, the selected texts, in espousing this concept of Bikolano sensibility have succeeded in liberating the postcolonial subject from cultural hegemony.

\section{Educational Implication to Real Life Situation from the Respondent's Experience}

In contemplating and judging the selected texts, readers are tempted to turn from the examination of these short stories mark with local color (Bikol language and myth). With the use of abrogation and appropriation of language, it fulfilled the needs of the meaning of the text to which the English language could not respond or justify the criteria used by the dominant culture in understanding the colonized/subaltern literature. The english language, or the so called colonized language becomes a site of struggle because it summons the absent colonizer and at the same time rejected the assumptions of traditional and fixed meaning of the subjected stereotypes, and finally asserts that regional and national literature written in various postcolonial englishes which have questioned the claim of English to assume the dominant status of a standard code the language of the erstwhile center.

The Bikol experience in every story traces a historical fact that Philippines is once then a colonized country that has gained independence after the three colonizers freed the Philippines from their bondage but even though colonization has already passed, the colonizer's culture comes out in the colonized subject's identity and culture. Hence, the selected short stories in demonstrate how the experience of colonization had shaped the Bikolano consciousness and ideology - the Bikolano sensibility. These sensibilities of the Bikolanos reflected from the selected texts mirrored the life of the Bikolanos in the real life context in which a currency of identity is imperative for a social and cultural negotiation between cultures. These realities from the selected texts are manifestations that literature imitates life.

On the other hand, while doing the process of literary analysis, there were twelve fourth year English majors who served as the respondents in the process of literary analysis. And here are some of the thoughts shared by the respondents in the process of literary analysis culled from the documentary survey:

Respondent 1: "The experience that I learned from this exercise is worthy in a way that it helps me to know the different 
theories embedded in the literary text. I could say that 'reader-response theory' is useful in analyzing a text because it affects our emotions in digging the deeper meaning of the text. The significance of this activity is that it pushes me to the limit in a way of getting the literal meaning of the text is not enough, you have to go deeper to get the sense of the text in a different way."

Respondent 2: "It is like filling the gap. At the start, I have only few knowledge about how to understand a literary piece but some information from the discussion, it gives me a lot of information."

Respondent 3: "We really have to secure a theory in order for us not to be subjective. We need to back up our claims with theory. With the short exposure with this activity, it build a foundation as to how should we interpret the data presented in the text and how this will help us to decipher the message, nor just its marginal message but more of its deeper meaning."

These responses established the assumption of scaffolding from constructivist point of view that there is better learning with a scaffold. The respondents were able to understand better the input when the teacher provided handouts to the students aside from the teacher-discussion. The teacher-made handouts guided the respondents of doing the task with ease because of the simplified discussion of the theory and presentation of model output. Nevertheless, contextualized instructional material aided the respondents of doing the task with less supervision and provided more room for the students to share their ideas in articulating the meaning of the texts.

\section{Proposed Content for the Lecture Note in Literary Criticism and Teaching of Literature Based from the Experience of the Respondents in Evaluating the Texts}

The access to quality education is a response to the view of equal opportunity and social literacy. This access provides opportunity for further significant improvement in quality offerings and instructional resources and materials for students who have limited access to foreign-authored textbooks. In this gap of resources, instructional material development is imperative. Material development is a process of creating IMs anchored on the needs of the target learners. The comprehensive development of the IM may include conceptualization, design, production and marketing. This material development is one of the mandates of the higher education to support the delivery of a curriculum and promote educational change and thereby disseminate these products to other SUCs, which are offering the same program and discipline.

In the process of conceptualizing this study, a need assessment was conducted to ensure the need of developing an instructional material in Teaching Literature and in Literary Criticism. There were 100 English majors used as respondents for the need assessment, grouped as follows: 57 freshmen, 33 sophomore and 10 juniors. These respondents noted that "learning is best achieved in the presence of sample output exercises reflected in the handouts (WM 1.29)" and "handouts promote the habit of selfindividualized learning (WM 1.38)," lastly, "teaching the theories requires textbooks and references (WM 1.49)". All responses with an interpretation of strongly agree.

There were also three experts in the field that evaluated the content validity of the two instructional materials: The Lectures on Discourse and Teaching of Literature. The instructional materials were evaluated on the following criteria: content, organization, effectivity and preference. The Lectures on Discourse was rated 4.30 while the Teaching of Literature was rated 4.28 both with an interpretation of very satisfactory, recommended for utilization if corrections are typographical in nature; then editors can correct them and return it to the writer then re-submit again the IM for further evaluation.

\section{Conclusion}

This paper aimed to develop content for a lecture note in Literary Criticism and Teaching of Literature. The study revolved in determining the cultural issues emerged from the selected texts particularly the symptoms of colonized (Bikolano) sensibility; and determine the educational implication of the cultural issues and sensibilities generated from the texts and its significance to the real life situation of the colonized subject. The formulation of the content of the proposed IM was based from the design of the curriculum in Literary Criticism and Teaching of Literature. The actual responses by the respondents from the analysis of selected stories help in contextualizing the chronology and possible content of the of the lecture notes. The various readings of the respondents creatively created multiple meanings 
with the use of postcolonial theory, which particularly produced sample analyses. The feedback of the fourth year English majors regarding the process of literary analysis were coded, sorted and categorized. There were three assumptions used in this study, namely: Homi Bhabha's (1994) postcolonial framework, which established the concept of postcolonial symptoms. John Dewey's (1933) constructivism provided guide in developing the content while Francis Johnson (1975) established the framing of the instructional material. At the end of this attempt, this paper hoped that it may open up a series of literary studies to other perspectives and multidisciplinary approaches and develop IM respectively that will further establish the colonized sensibility of the stereotype subject and develop instructional materials generated from the exercises made by the students to serve as additional reference in appreciating literary criticism and literature especially for a student-directed group environment.

\section{Cultural Issue and Sensibility}

The cultural issues emerged from the texts are hybridity, ambivalence and displacement. These issues are closely interwoven which foregrounds similar postcolonial symptoms, like the sensibility of the characters. These characters prove their currency in the colonial context, as in the case of the local chanter who uses her Bikol tongue and multicultural characteristics in her cultural negotiation, while the fish-hair woman deconstructs her identity to portray a patriarchal order. The Bikol characters' displacement, by geographic separation, culture or identity speak nourishment of their hybridity in a foreign land or man's dominated culture as the totally fragmented Self, which must not be read as a revelation of some suppressed truth of the postcolonial subject, who looks no different from the metropolitan intellectual with the ambivalence of his/her desire for the Other. Bhabha's concept on ambivalence, hybridity and displacement is manifested in the sensibilities of the Bikolanos in getting along with the Westerns and adapting to new environment/culture and yet retaining the local culture. Each time this encounter between Self and Other occurs at the point at which something exceeds the frame of the image (as in the case of the stories analyzed in this research), it evacuates the Self as the site of identity and autonomy and leaves a mark of the subject, a sign of a local identity - the Bikolano sensibility. This becomes the moment in which the demand for identification takes the form of a response to other questions of signification and desire, culture, and politics. The use of Bikol/Filipino language in the texts asserts this question of subjected signification to speak against the superiority of the Westerns (colonizers) over the Third World countries (colonized). The characters in the selected stories have demonstrated superiority of the Bikol characters in their negotiation against imperial culture through abrogation and appropriation of the language. Moreover, the concurrent presence of the submission and resistance to different cultures creates a fusion of unique cultural hybridity, ambivalence and displacement, or what Bobis calls a "negotiation between cultures". This social and cultural negotiation uncovered a unique hybrid culture which opposes and at the same time supports the dominance of neo-colonialism and patriarchy, treading on the boundary between domination and resistance, a cultural identity which altered both subjected stereotypes (colonizer and colonized), dominant over marginalized culture because of the effect of transference.

Through the selected stories, this study was able to prove successfully that there is a Bikolano sensibility that exists beyond the stereotypes created from the fusion of the colonizers and colonized's identity and culture - a hybrid and ambivalent identity and culture. This is an identity that cannot be neatly defined, but the border that created the emergent hybrid culture and identity transcends this definition. The Filipino is not just brown-skinned, but may also be fair skinned. Filipinos do not only do the honest job of housekeeping, but they are also poets, writers, entrepreneurs, political leaders and the like which are also evident among the superior stereotypes. This is a sensibility that is continually being re-discovered by the colonized themselves, who have assimilated mentally even during and after the propagation of superiority of the colonizers.

In contemplating and judging Merlinda Bobis works, readers are tempted to turn from the examination of her short stories mark with local color (Bikol language and myth) and the author herself as a representation of postcolonial literature and of an Asian as a whole. With the use of Bobis's abrogation and appropriation of language, it fulfilled the needs of the meaning of the text to which the English language could not respond or justify the criteria used by the dominant culture in understanding the colonized/subaltern literature. The english language, or the so called colonized language becomes a site of struggle because it summons the absent colonizer and at the same time rejected the assumptions of traditional and fixed meaning of the subjected stereotypes, and finally asserts that regional and national literature written in various postcolonial englishes which have questioned the claim of English to assume the dominant status of a standard code the language of the erstwhile center. 
The selected short stories demonstrate how the experience of colonization had shaped the Bikolano consciousness and ideology - the Bikolano sensibility. The Bikolano sensibility is a currency of the Bikol character in his/her social and cultural negotiation between cultures. Bobis has abrogated and appropriated the English language by fusing the Bikol/Filipino language and asserted that English language could not fully appropriate the colonized meaning and language. This notion articulates the Bikol tongue/language to demonstrate the life and culture of the colonized and reveal the currency of stereotype, which alters the subjective signification of the imperial culture that the colonized are inferior and the colonizers are superior. The Bikolano sensibility is the avenging power to show that the colonized appear superior over the colonizer, for without the colonized, the superiority of the colonizer will be silenced by the absence of the colonized. The conditioning that occurred in the process of colonization makes the Bikol characters speak of the power and authority of the colonizers on one hand and the colonizer on the other hand, speak the sensibility of the colonized, because during the colonization, the transference of culture takes place and creates a border, a border between the colonized and colonizer, that in the long run, one could not anymore speak of pure identity/culture because both are already hybrid in nature.

The selected texts have documented a hybrid approach of interpellation from the conventional concept of articulation like that of tracing the influence of the writer to his/her texts that somehow the writer has an unconscious contribution of his/her life to the textuality of the text - a space of intervention which may establish a hybrid culture or the Other. This hybridity demonstrates a notion which is not an identification of binary oppositions, but rather, going beyond it by decentering the center through a fusion of cultures. This hybrid culture is neither the dominant nor the emergent opposition to it. It belongs to the boundary between the two. Minh$\mathrm{Ha}$ argues that "the hybrid culture/individual who stands in that undetermined threshold where he/she constantly drifts in and out, which at the same time undercuts the inside/outside opposition, his/her intervention is necessarily that of both a deceptive outsider whether he/she turns the inside out or the outside in." This hybrid culture/individual is, like the two sides of a coin, the same impure, both in one, the insider/outsider.

\section{Educational Implication}

The meaning generated from the selected passed through a process, which started from reading and analysis of the text, and ended with a documentary survey on the actual experience and challenges encountered by the respondents in the literary analysis. The respondent's feedback resembles the proposed content of the lecture note in Literary Criticism and Teaching of Literature. Hence with the foregoing merits from the literary analysis, literature teachers have to perform a big role in providing relevant experiences to the students, which are challenging and at the same time an opportunity to appreciate the breadth and depth of literature particularly on Bikol literature. The experience of the respondents in analyzing the selected texts gave them the realization in evaluating the merit of literature along various aspects such as how postcolonial theory is being used in analyzing the text, the importance of having a background on the elements of fiction and poetry and during the FGD session the respondents were able to figure out the importance of having a prototype output while doing their individual task. In the process of literary analysis, students are expected to demonstrate the $21^{\text {st }}$ century skills - language skill, critical thinking, management of affective factors and performance skill. The actual experience of the students in analyzing the texts with limited resources revealed a limitation in the literary analysis. The direct delivery of instruction aided the students with the principle of literature, and the provision of handout in literary analysis, which includes enabling activities help the students to work independently.

\section{Proposed Content}

Course Outline: This refers to the coverage of the topics and requirement of the course. This outline provides the chronological entry of topics and time duration.

Brief Discussion of Subject Matter: These are the major topics, which have been divided and subdivided into suitable sections for easy reading.

Text and Question: These are the specimens that will be used by the learners and each text includes guide questions as basis for reflection on what they have read.

Example Final Output: These are the model literary analysis made by the respondents which serve as illustrations or example.

Enabling Activity: These are set of activities, which provide the readers a chance to apply new knowledge and skills in their analysis.

Evaluation: This refers to the assessment from each activity.
Literary Criticism

Introduction to Literary

Criticism

Elements of Fiction and
Teaching of Literature

Introduction to

Literature

Lesson Planning 
Poetry

Lecture 1: Reader

Oriented Approach

Lecture 2: Poststructuralist

Theory

Lecture 3: Deconstruction

Lecture 4: Postcolonial

Theory

Criteria of Selection

Choices for Study

Basic Strategies and

Approaches in

Teaching Literature

Dynamics in Teaching

Poetry

Dynamics in Teaching

Fiction

\section{Recommendation}

With the foregoing conclusion, this study recommends further studies on the other works of Bikol writer to demonstrate another territory of translation and testimony of analytical argument or framework such as: works of other Bikol writers to further validate the Bikolano sensibility; works of other Filipino authors belonging to other regions or cultural communities which interpellate dominance of the Western; and other writing style to unveil more complex colonial configurations in the Philippine context. Moreover, this researcher hopes that this paper may open up a series of literary studies to other perspective and multidisciplinary approaches that will further establish the Third World claim regarding the subaltern identity subjected to us by the imperial culture especially on the identification of Bikolano/Filipino sensibility in Philippine fiction in English of other Bikol/regional writers, and may contribute to a fuller understanding of the different questions posed by postcolonial literature and criticism. Finally, this paper hopes to add supplemental material in Literary Criticism and Teaching of Literature through lecture note that will aid the student-directed environment.

\section{References}

Bill Ashcroft, Gareth Griffiths \& Helen Tiffin, (1989). The empire writes back: theory and practice in post-colonial literatures. London and New York: Routledge.

Danilo V. Rogayan, (2018). "Development and Validation of Physical Science Workbook for Senior High School", Science Education International, Vol 30 , Issue 4.

Emira Derbel (2019). "Teaching Literature through Comics: An Innovative Pedagogical Tool", International Journal of Applied Linguistics \& English Literature, AIAC.

Geraldine Alvina, (2012). "Understanding Culture through the Language of Oral Narratives".

Homi K. Bhabha, (1996). "Caliban Speaks to Prospero: Cultural Identity and the Crisis of Representation", Mariani, Critical Fictions, ed. Padmini Mongia, Contemporary Postcolonial Theory: A Reader, New York: Hodder Headline Group.

Homi K. Bhabha, (1995). "Signs Taken for Wonder" in the Post-colonial studies reader, ed. Bill Ashcroft, Gareth Griffiths and Helen Tiffin. London and New York: Routledge.

Homi K. Bhabha. (1994). The location of culture, London and New York: Routledge.

John Wilson Brucal, Ann Krissabelle Quilaton, Jamaica Tampucao \& Ernesto Mandigma. (2018) "Instructional Materials in Teaching Literature in the Unified Schools of the Archdiocese of Lipa", International Journal of Recent Innovations in Academic Research.

Merlinda Bobis, (2001), "Myth and Mythologizing in White Turtle", Conference Paper in Trading in Imagination, Power House Museum.

Merlinda Bobis, (2001). "Trading in Imagination", Conference Paper, Power House Museum.

Merlinda Bobis, (1999). White turtle, Manila: De La Salle University Press.

Nora Marasigan, (2019). "Development and Validation of a Self-Instructional Material on Selected Topics in Analytic Geometry Integrating Electronic Concepts", International Journal of Recent Innovations in Academic Research.

Susan Lenski, Mindy Larson, Dot McElhone, Dennis Davis, Carol Lauritzen, Amanda Villagomez, Maika Yeigh, Melanie Landon-Hays, Marie Lejeune \& David Scales, (2016). "What Teachers Want: A Statewide Survey of Reading and English Language Arts Teachers' Instructional materials, Preferences, and Practices", Literacy Research Instruction, Routledge.

\section{Acknowledgment}

The researcher wishes to extend his gratitude to the CBSUA-Sipocot Campus, particularly the Research Division for accepting his research proposal for evaluation. Moreover, to his wife - Abby and daughter - Danielle Angela who continuously give him inspiration to work harder and perform duties with a light heart; moreover, to his CBSUA family for the healthy professional partnership. 